\title{
Finite element analysis for czochralski growth process of sapphire single crystal
}

\author{
S.J. Lim, H.Y. Shin, J.H. Kim and J.I. $\mathrm{Im}^{\dagger}$ \\ Simulation Center, Business Support Div., KICET, Seoul 153-801, Korea \\ (Received September 27, 2011) \\ (Revised October 4, 2011) \\ (Accepted October 7, 2011)
}

\begin{abstract}
Recently sapphire crystals are used in LED applications. The Czochralski (CZ) growth process is one of the most important techniques for growing high quality sapphire single crystal. A successful growth of perfect single crystals requires the control of heat and mass transport phenomena in the $\mathrm{CZ}$ growth furnace. In this study, the growth processes of the sapphire crystal in an inductively heated $\mathrm{CZ}$ furnace have been analyzed numerically using finite element method. The results shown that the high temperature positions moved from the crucible surface to inside the melt and the crystalmelt interface changed to the flat shape when the rpm was increased. Also the crystal-melt interface shape has been influenced by the shoulder shape of the grown crystal during the initial stage.
\end{abstract}

Key words Sapphire, Czochralski process, FEM, Crystal-melt interface, rpm, Shoulder

\section{사파이어 단결정의 초크랄스키 성장공정에 대한 유한요소분석}

임수진, 신호용, 김종호, 임종인

한국세라믹기술원 기업지원본부 시뮬레이션센터, 서울, 153-801

(2011년 9월 27일 접수)

(2011년 10월 4일 심사완료)

(2011년 10월 7일 게재확정)

요 약 최근 사파이어 결정은 $\mathrm{LED}$ 응용부품에 사용되고 있고, $\mathrm{CZ}$ 성장공정은 고 품질의 사파이어 단결정을 성장시키 기 위한 중요한 기술중의 하나이다. 고 품질의 단결정을 성장하기 위해서는 $\mathrm{CZ}$ 성장로 내부의 열 및 질량 전달현상의 제 어가 필요하다. 본 연구에서는 유도 가열된 $\mathrm{CZ}$ 성장로에 대한 사파이어 결정의 성장공정을 $\mathrm{FEM}$ 을 사용하여 수치적으로 분석하였다. 본 연구의 결과, 성장로의 $\mathrm{rpm}$ 이 증가함에 따라 고온부는 도가니 표면에서 융액의 내부로 이동하고, 고-액 계 면은 평편한 형태로 변화되는 것으로 분석되었다. 또한 성장된 결정의 고-액 계면은 초기에 형성된 결정의 shoulder 형상에 의해서도 영향을 받는 것으로 나타났다.

\section{1. 서 론}

최근 $\mathrm{LED}$ 기판용 주목을 받고 있는 사파이어 단결정 $\left(\mathrm{Al}_{2} \mathrm{O}_{3}\right)$ 은 hexagonal 결정구조를 가지고 있고, 결정면 방위에 따라 다양한 용도로 사용되고 있다. 사파이어의 $\mathrm{c}$ 결정면은 $\mathrm{LED}$ 기판용으로, $\mathrm{a}$ 결정면 등은 $\mathrm{LCD}$ 및 광 학용, 내화학용 등으로 사용되고 있다. 이러한 사파이어 단결정의 성장기술로는 Bridgman법, $\mathrm{CZ}$ (Czochralski)법, Kyropoulus법, EFG(Edge-defined Film-fed Growth)법,

Corresponding author

Tel: +82-2-3282-2491

Fax: +82-2-3282-7801

E-mail: jongin@kicet.re.kr
$\operatorname{HEM}($ Heat Exchange Method) 등 다양한 기술이 적용 되고 있다[1].

$\mathrm{CZ}$ 성장법은 융액에서 단결정을 성장시켜 수직으로 인상하므로 c축으로 배향된 실린더형 사파이어 단결정 을 대량 성장시킬 수 있는 중요한 기술중의 하나이다. 융액을 성장로 내부의 실린더형 도가니에 위치시키고, $\mathrm{RF}$ 유도가열 방식으로 융점 온도이상으로 가열시킨다. 단결정의 품질은 성장로 내부의 열 이력 및 물질 전달 현상과 아주 밀접한 관계가 있고, 고품질의 단결정을 제조하기 위해서는 이들 현상에 대한 제어가 아주 중요 하다.

$\mathrm{CZ}$ 성장로 내부의 열의 대류 및 전도, 복사현상은 결정성장 공정의 열이력 특성에 직접적인 영향을 미친 
다. 또한 열이력 특성은 성장로의 형상 및 열원 위치, 도가니 및 단열제의 배치 등 많은 요인에 의하여 많은 영향을 받는다 $[2,3]$. 그러므로 사파이어 $\mathrm{CZ}$ 성장공정 을 잘 제어하기 위해서는 단결정이 성장되는 전 공정 에 대한 열원 및 열/물질 전달 현상에 대한 분석이 필 수적이다.

지금까지 실리콘 등 단결정에 대한 $\mathrm{CZ}$ 성장공정에 대 한 수치 해석은 많이 보고 되었지만, 사파이어CZ 결정 성장공정에 대한 시뮬레이션은 거의 이루어지지 않았다. 최근에 Tavakoli[2] 및 $\mathrm{Lu}$ 등[3]은 사파이어 $\mathrm{CZ}$ 결정 성장공정 중 열 전달 및 유체 유동, $\mathrm{RF}$ 코일 위치 영향 등을 2 차원 수치해석으로 성공적으로 분석하였다고 보고 하였다. 이들 연구는 $\mathrm{RF}$ 유도가열의 $\mathrm{CZ}$ 결정 성장공정 을 해석한 것으로는 큰 의미가 있지만, 실제적인 사파이 어 $\mathrm{CZ}$ 결정 성장공정에 적용하기에는 다소 부족하다고 판단된다.

본 연구에서는 실질적인 사파이어 성장에 적용하기 위 하여 전체 $\mathrm{CZ}$ 성장공정을 $\mathrm{FEM}$ 을 사용하여 수치적으로 분석하고자 하였다. 이를 위하여 $\mathrm{RF}$ 방식의 실제 $\mathrm{CZ}$ 성장로 전체를 모델링하고, 단결정의 성장 초기부터 말 기까지 열 유동특성 및, 단결정의 형상 등을 분석하고자 하였다. 또한 $\mathrm{CZ}$ 성장공정 중 $\mathrm{RPM}$ 및 성장된 결정의 shoulder 형상이 성장중인 결정의 고-액 계면의 형상에

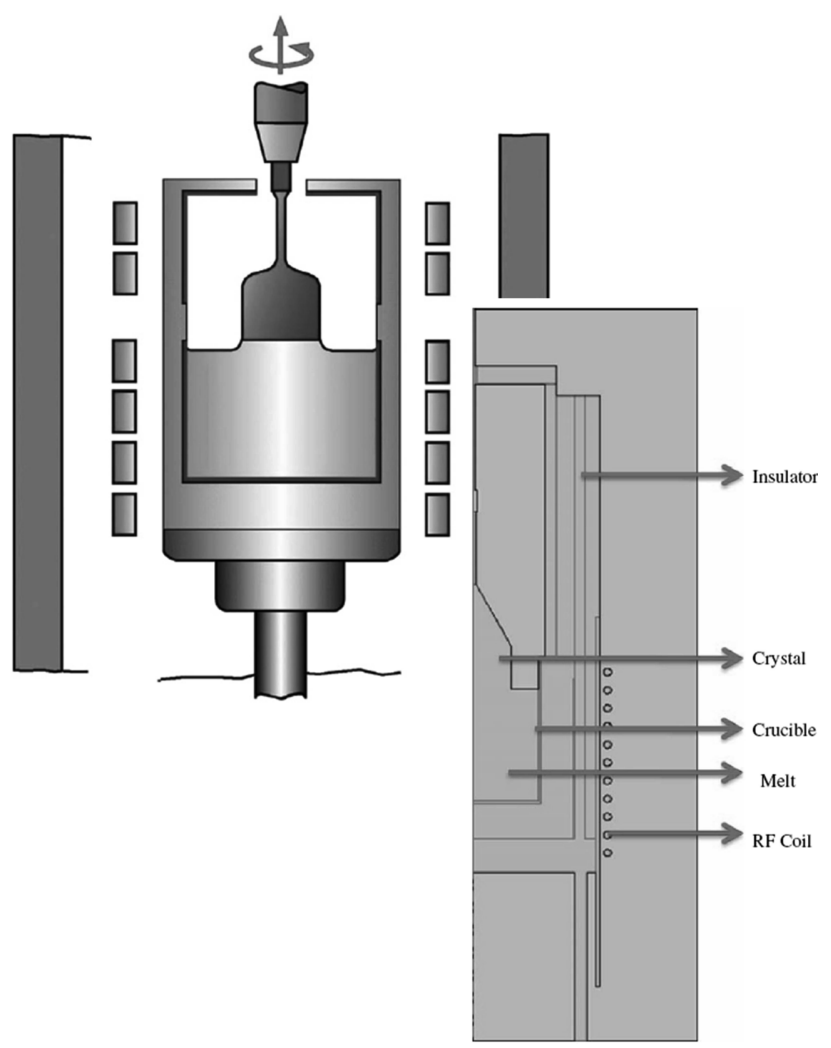

Fig. 1. Schematic diagram of the $\mathrm{CZ}$ growth system for the sapphire crystal $[2,3]$.
어떠한 영향을 미치는지 분석하고자 하였다.

\section{2. 수치해석 모델}

사파이어 $\mathrm{CZ}$ 성장로는 Fig. 1에 나타낸 바와 같이 $\mathrm{RF}$ 유도 코일 및 단열재, 도가니, 융액, 결정, 지지부 등 으로 구성되어 있다. $\mathrm{CZ}$ 성장로를 수치해석 하기 위해 내부는 진공 중이라 가정하였고, $\mathrm{RF}$ 유도 코일은 원형 으로 배열되어 있다. 또한 사파이어 $\mathrm{CZ}$ 성장로의 유체 유동 및 열 전달은 축대칭으로 가정하여 해석한다.

$\mathrm{RF}$ 유도 가열의 경우, 모든 구성 재료는 등방성 비자 성체이고, $\mathrm{RF}$ 코일의 전류 및 전압 분포는 균일하며 전 자기장은 도가니 및 히터의 온도와는 무관하다고 가정하 였다. $\mathrm{RF}$ 유도가열에 대한 전자기장 지배방정식 $[2,3]$ 은

$$
\mathrm{j} \omega \sigma_{\mathrm{c}}(\mathrm{T}) \overrightarrow{\mathrm{A}}+\nabla \times\left(\frac{1}{\mu_{0}} \nabla \times \overrightarrow{\mathrm{A}}\right)=0
$$

이고, $j$ 는 conjugate, $\vec{A}$ 는 자기폰텐셜 벡터, $\omega$ 는 각 주 파수, $\mu_{0}$ 는 진공 투자율, $\sigma_{\mathrm{c}}$ 는 전기전도도를 의미한다. 그리고 이리듐(Ir) 도가니의 전기전도도는

$$
\sigma_{c}(T)=\frac{1}{\rho_{0}\left(1+\alpha_{r}\left(T-T_{0}\right)\right)}
$$

와 같이 나타내어 진다. 여기서 $\rho_{0}$ 및 $\alpha_{\mathrm{r}}$ 은 각각 실온에 서의 전기저항 및 전기저항의 온도계수를 의미하고, $\mathrm{T}$ 및 $\mathrm{T}_{0}$ 는 각각 실제 온도 및 실온을 의미한다. 또한 $\mathrm{AC}$ 전류에 의한 $\mathrm{Ir}$ 도가니의 유도가열 열량은 $\left(\mathrm{Q}_{\mathrm{ind}}\right)$ 은

$$
\mathrm{Q}_{\text {ind }}=\frac{1}{2} \sigma_{\mathrm{c}}|\overrightarrow{\mathrm{E}}|^{2}
$$

과 같이 표현되고, $\overrightarrow{\mathrm{E}}$ 는 $\mathrm{RF}$ 코일의 자기장에 의해 유도 된 전기장 포텐셜을 의미한다.

$\mathrm{CZ}$ 성장로 전체 시스템의 열 전달은 전도 및 복사에 의한 고체간의 열 교환 등에 의해 이루어지고, 이에 대 한 지배방정식[4]은

$$
\nabla \cdot(\mathrm{k} \nabla \mathrm{T})-\mathrm{Q}=0
$$

와 같다. 여기서 $\mathrm{Q}$ 는 열원의 발생 총 열량, $\mathrm{k}$ 는 온도에 의존하는 열전도도를 의미한다. 그리고 고체 표면간의 복사 열 교환에 대한 지배방정식은 Stephan-Botzman 법 칙에 의해 다음 식과 같이 나타낼 수 있다.

$$
\mathrm{Q}^{\text {out }}=\varepsilon \mathrm{C}_{\mathrm{SB}} \mathrm{T}^{4}+(1-\varepsilon) \mathrm{Q}^{\text {in }}
$$

여기서 $\mathrm{Q}^{\text {out }}$ 및 $\mathrm{Q}^{\text {in }}$ 은 각각 표면에서 방출 및 유입되는 복사 열이고, $\varepsilon$ 은 방사도, $\mathrm{C}_{\mathrm{SB}}\left(=5.67 \times 10^{-8}\left(\mathrm{~W} / \mathrm{m}^{2} \mathrm{C}^{4}\right)\right)$ 는 StephanBotzman 상수를 의미한다. 그리고 특정 표면에 유입되 
는 전체 복사열은 성장로의 디자인 및 모델에 따른 영향 을 받는 분포인자를 곱하여 계산할 수 있다.

결정 및 융액을 포함하는 결정화 영역에서의 준안정 상태이고, 융액은 비압축성 Newtonian 유체로 가정하였 으며, 융액의 내부 복사는 무시하였고, 융액의 표면은 편 평하다고 가정하였다. 결정화 영역의 열 전달 및 물질 이동에 대한 지배방정식은 다음과 같다[2-4].

$$
\begin{aligned}
& \nabla \cdot \overrightarrow{\mathrm{u}}=0 \\
& \rho_{l} \frac{\mathrm{d} \overrightarrow{\mathrm{u}}}{\mathrm{dt}}=-\nabla \mathrm{p}+\nabla \cdot\left(2 v_{\mathrm{eff}} \dot{\mathrm{S}}+\rho \beta\left(\mathrm{T}_{\mathrm{m}}-\mathrm{T}\right)\right) \overrightarrow{\mathrm{g}} \\
& \rho_{l} \mathrm{C}_{\mathrm{p}} \frac{\mathrm{dT}}{\mathrm{dt}}=\nabla \cdot\left(\mathrm{k}_{\mathrm{eff}} \nabla \mathrm{T}\right)-\nabla \cdot \overrightarrow{\mathrm{Q}_{\mathrm{r}}}
\end{aligned}
$$

여기서 $\rho_{l}$ 는 융액의 밀도, $\overrightarrow{\mathrm{u}}$ 는 속도, $\overrightarrow{\mathrm{g}}$ 는 중력, $\mathrm{p}$ 는 압 력, $\overrightarrow{\mathrm{Q}_{\mathrm{r}}}$ 은 복사열 벡터, $\beta$ 는 열팽창계수, $\mathrm{S}$ 는 변위 속 도 텐서, $v_{\mathrm{eff}}$ 는 유효 동적 점도, $\mathrm{C}_{\mathrm{p}}$ 는 비열, $\mathrm{T}$ 는 온도, $\mathrm{T}_{\mathrm{m}}$ 은 사파이어의 용융 온도, $\mathrm{k}_{\mathrm{eff}}=\mathrm{k}+\mathrm{v} / \mathrm{P}_{\mathrm{r}}$ 은 유효 열전 도도, $\mathrm{P}_{\mathrm{r}}=0.9$ 는 터블런스 Prandtl 상수를 의미한다. 그 리고 유도 가열된 도가니 및 결정, 나머지 고체 부분에 대한 지배방정식은 각각 다음과 같이 나타내어진다.

$$
\begin{aligned}
& -\nabla \cdot\left(-\mathrm{k}_{\text {cru }} \nabla \mathrm{T}\right)-\mathrm{Q}_{\text {ind }}=0 \\
& \rho_{\text {crystal }} \mathrm{C}_{\text {crystal }} \overrightarrow{\mathrm{u}}_{\mathrm{p}} \cdot(\nabla \mathrm{T})-\nabla \cdot\left(\mathrm{k}_{\text {crystal }} \nabla \mathrm{T}\right)=0 \\
& -\nabla \cdot\left(-\mathrm{k}_{\text {solid }} \nabla \mathrm{T}\right)=0
\end{aligned}
$$

여기서 $\rho_{\text {crystal }}$ 및 $\mathrm{C}_{\text {crystal }}$ 는 각각 사파이어의 밀도 및 비열 이고, $\overrightarrow{\mathrm{u}}_{\mathrm{p}}$ 는 결정의 성장 속도를 나타낸 것이다.

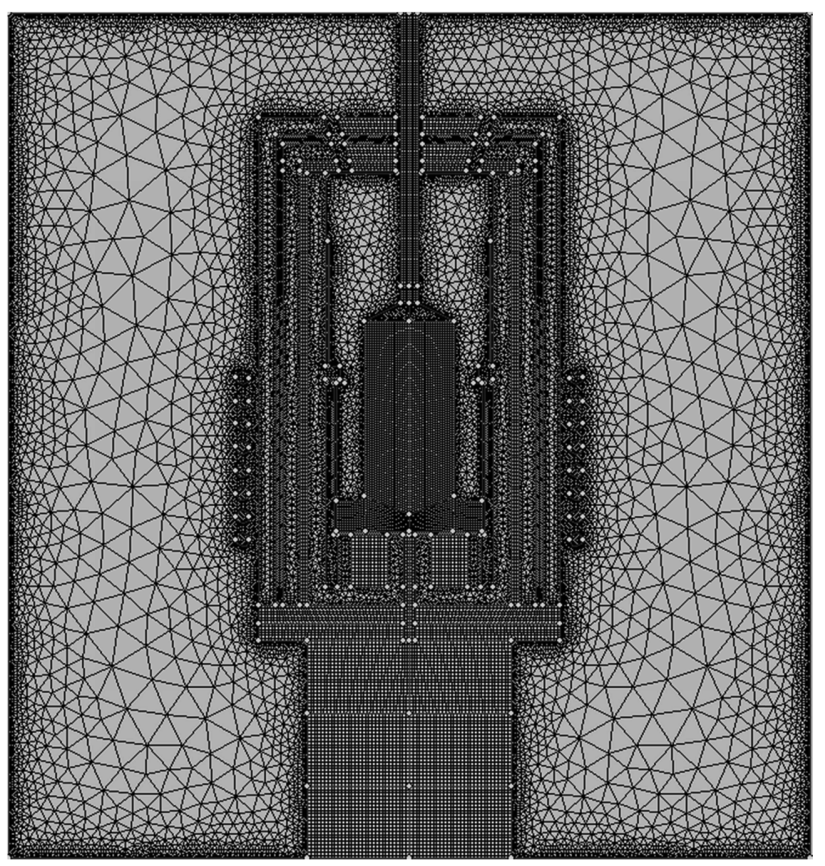

Fig. 2. Finite element model of the $\mathrm{CZ}$ growth system.

\section{3. 결과 및 고찰}

사파이어 $\mathrm{CZ}$ 성장로의 내부특성의 분석을 위해서는 $\mathrm{RF}$ 유도발열에 의한 내부 온도분포 및 융액 유동특성, 성장된 결정 형상 등에 대한 고려가 필요하다. 본 연구 에서는 $\mathrm{CZ}$ 성장로의 열 유동특성 분석을 통해 사파이어 결정의 성장시 단계별 결정의 형상을 분석하였고, 결정

Table 1

Thermo-physical properties of the constitutional material for CZ growth system [Ref. 2-4]

\begin{tabular}{lll}
\hline Materials & Properties & Values \\
\hline Sapphire & Melting temperature $(\mathrm{K})$ & 2323 \\
& Density $\left(\mathrm{kg} / \mathrm{m}^{3}\right)$ & Melt: $3,030 /$ Crystal: 3,970 \\
& Thermal conductivity $(\mathrm{W} /(\mathrm{m} \cdot \mathrm{K}))$ & Melt: $3.5 /$ Crystal: 17.5 \\
& Specific heat capacity $(\mathrm{J} /(\mathrm{kg} \cdot \mathrm{K}))$ & Melt: $1,430 /$ Crystal: 1,260 \\
& Latent heat $(\mathrm{J} / \mathrm{kg})$ & $1,067,700$ \\
& Viscosity $(\mathrm{Pa} \cdot \mathrm{s})$ & $0.0475 /$ Dynamic: 0.057 \\
& Thermal expansion coefficient $(1 / \mathrm{K})$ & $5.0 \mathrm{e}-6$ \\
& Emissivity & Melt: $0.33 /$ Crystal: 0.869 \\
\hline Insulator & Density $\left(\mathrm{kg} / \mathrm{m}^{3}\right)$ & $3,500 \sim 6,000$ \\
& Thermal conductivity $(\mathrm{W} /(\mathrm{m} \cdot \mathrm{K}))$ & $0.048 \sim 1.8$ \\
& Specific heat capacity $(\mathrm{J} /(\mathrm{kg} \cdot \mathrm{K}))$ & $200 \sim 780$ \\
\hline Ir crucible & Density $\left(\mathrm{kg} / \mathrm{m}^{3}\right)$ & 22,400 \\
& Thermal conductivity $(\mathrm{W} /(\mathrm{m} \cdot \mathrm{K}))$ & 147 \\
& Specific heat capacity $(\mathrm{J} /(\mathrm{kg} \cdot \mathrm{K}))$ & 130 \\
\hline RF coil & Density $\left(\mathrm{kg} / \mathrm{m}^{3}\right)$ & 8,930 \\
& Thermal conductivity $(\mathrm{W} /(\mathrm{m} \cdot \mathrm{K}))$ & 384 \\
& Specific heat capacity $(\mathrm{J} /(\mathrm{kg} \cdot \mathrm{K}))$ & 340 \\
\hline
\end{tabular}


Table 2

Geometry and operating parameters used for the calculation

\begin{tabular}{lll}
\hline Parts & Properties & Values \\
\hline Crucible & Height $(\mathrm{mm})$ & 170 \\
& Inner radius $(\mathrm{mm})$ & 82 \\
& Thickness $(\mathrm{mm})$ & 3 \\
\hline \multirow{2}{*}{ RF coils } & Height $(\mathrm{mm})$ & 285 \\
& Inner radius $(\mathrm{mm})$ & 180 \\
& Thickness $(\mathrm{mm})$ & 15 \\
\hline Current & Frequency of RF coil $(\mathrm{kHz})$ & $8 \sim 10$ \\
\hline Ambient temp. & $\left({ }^{\circ} \mathrm{C}\right)$ & 25 \\
\hline
\end{tabular}

의 회전속도 및 shoulder 형상 등이 성장된 결정의 형상 에 미치는 영향을 주는지 분석하였다.

본 연구에서 사용한 $\mathrm{CZ}$ 성장로 시스템에 대한 FEM 모 델을 Fig. 2에 나타내었고, 성장로 시스템의 구성 부품에 대한 열 물성 및 구성부품의 형상, 가동 조건 등을 각각 Table 1과 2에 나타내었다. 사파이어 결정 성장 전 융액 높 이는 $285 \mathrm{~mm}$ 이고, 성장된 결정의 직경은 $100 \mathrm{~mm}$ 이었다.

$\mathrm{RF}$ 유도 가열에 의한 $\mathrm{CZ}$ 성장로의 전체적인 온도분포를 분석하고, 그 결과를 Fig. 3 에 나타내었다. 여기에서 알 수 있듯이, 도가니 내부 온도는 RF 코일 전류에 의한 $\mathrm{Ir}$ 도가 니의 발열 때문에 가장 높고, 단열재 외부는 열 전달이 차 단되기 때문에 상대적으로 낮은 온도분포를 보이고 있다.

Fig. 4에는 사파이어 결정의 성장 단계별 온도분포 및 융액 유동특성, 결정의 형상 등을 분석한 결과를 나타내 었다. 결정 성장 초기 경우, 융액은 약 2361 2422 K 사 이로 도가니 근처 측면의 온도가 가장 높고, 바닥부가 가장 낮은 온도 분포를 가지고 있는 것으로 분석되었다. 이러한 온도분포 때문에 융액의 유동은 도가니 상부 측
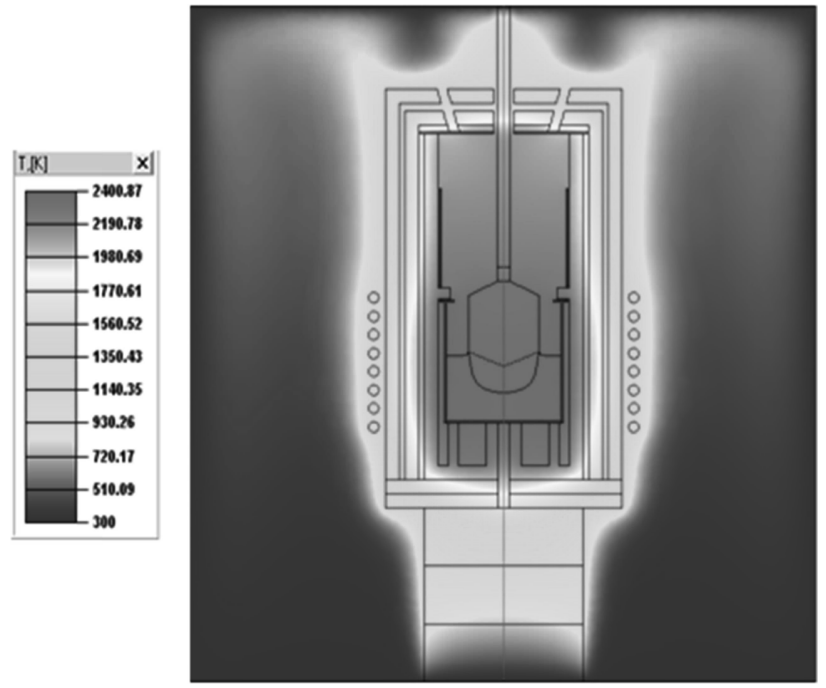

Fig. 3. Simulated temperature distributions of the $\mathrm{CZ}$ growth system at the mid stage.

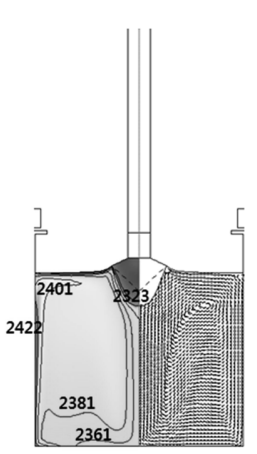

(a)

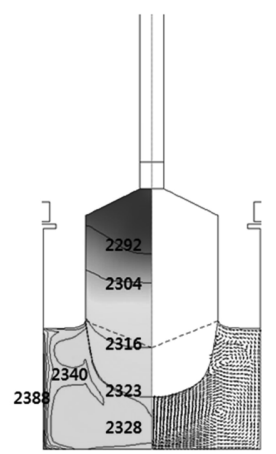

(b)

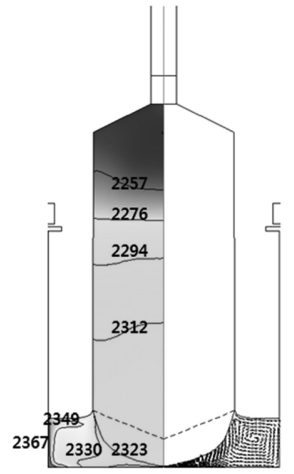

(c)
Fig. 4. Simulated crystal shape of the sapphire during the growth stage: (a) initial stage, (b) mid stage, and (c) final stage.

면에서 내부 방향으로 유동이 발생하는 것으로 나타났다. 성장 중기 경우, 융액 내부는 약 2328 2388 K 정도로 온도분포를 갖는 것으로 해석되었고, 융액은 시계 반대 방향으로 상부 및 하부에 두 개의 유동 패턴이 발생하는 것으로 분석되었다. 또한 성장된 결정은 약 2323 2292 K 정도의 온도 분포를 갖는 것으로 분석되었다. 결정 성장 말기 경우, 융액 및 성장 결정은 각각 약 2330 2367 K 정도 및 약 2323 2257 K 정도의 온도분포를 갖는 것으 로 분석되었다. 즉 $\mathrm{CZ}$ 성장로 시스템을 이용하여 사파 이어 단결정을 성장시킬 경우, 성장이 진행됨에 따라 융 액 내부의 온도차는 감소하고, 성장된 결정 내부의 온도 차는 증가한다. 또한 성장 초기에는 시계 반대방향의 커 다란 열유동 패턴을 보이다가 성장 중기에는 두 개의 열

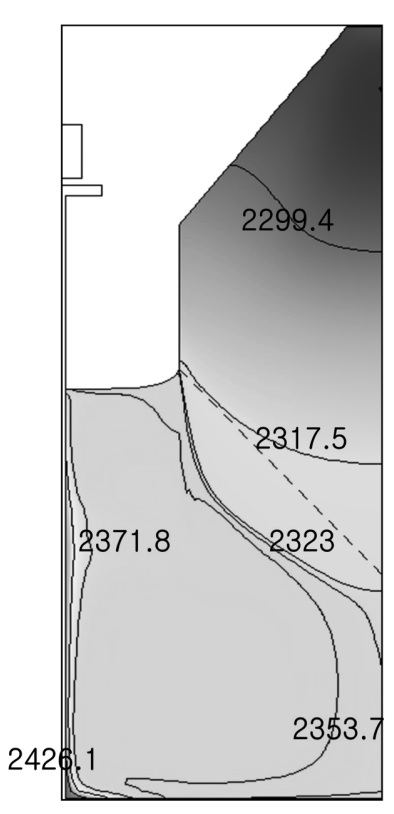

(a)

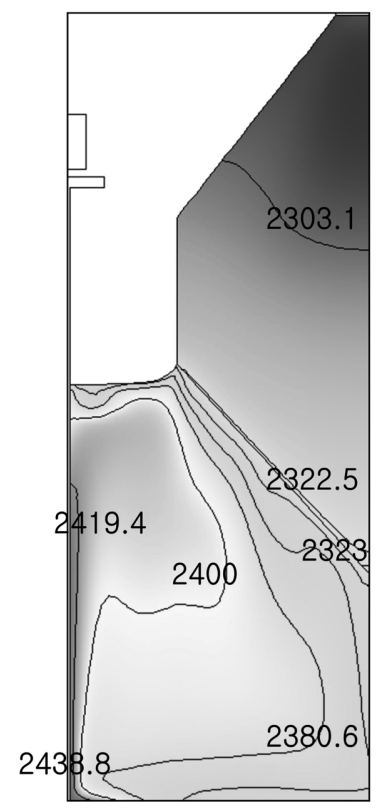

(b)
Fig. 5. Influence of the rpm on the crystal shape during the mid stage: (a) $1 \mathrm{rpm}$ and (b) $10 \mathrm{rpm}$. 
유동 패턴으로 분리되는 현상이 나타난다. 이러한 유동 패턴은 $\mathrm{RF}$ heter의 가열조건 및 성장로의 구조 등을 조 정함으로써 제어가 가능할 것으로 판단된다.

사파이어 $\mathrm{CZ}$ 성장공정 중 결정의 회전속도를 $1 \mathrm{rpm}$ 부 터 $10 \mathrm{rpm}$ 까지 변화시키면서 융액 및 결정의 내부 온도 분포 및 고-액 계면 모양을 분석한 결과를 Fig. 5 에 나 타내었다. 결정의 회전속도가 $1 \mathrm{rpm}$ 에서 $10 \mathrm{rpm}$ 으로 증 가함에 따라 용융 melt 온도의 분포는 전체적으로 올라 가고, 고-액 계면 근처에서 온도도 증가하는 것으로 분 석되었다. 또한 결정의 회전속도가 증가함에 따라 고-액 계면의 모양도 round형에서 sharp한 flat형으로 변화되는 것으로 분석되었다. 또한 낮은 $\mathrm{rpm}$ 에서는 많은 와류형 상의 유동 패턴이 보이지만 결정의 회전속도가 $6 \mathrm{rpm}$ 이상이 되면 단일 형상의 유동 패턴으로 변경되는 것을 확인하였다. 이상의 결과를 종합하여 볼 때, 결정의 회전 속도가 증가함에 따라 melt 및 결정 내부의 온도가 전체 적으로 증가하게 된다. 또한 융액의 유동 속도 및 패턴 이 변경되어 상대적으로 결정화 영역이 감소하기 때문에 결정의 고-액 계면의 모양도 round형에서 sharp한 flat형 으로 변화되는 것으로 판단된다.

사파이어 $\mathrm{CZ}$ 제조공정 중 초기에 형성된 Shoulder 모 양이 성장된 결정의 형상에 미치는 영향을 분석하고, 그 결과를 Fig. 6에 나타내었다. 여기에서 알 수 있듯이, Shouler 모양을 flat한 형태에서 round한 형태로 변경함 에 따라 melt 및 결정 내부의 온도가 약간 감소하는 것 으로 분석되었고, 성장된 결정의 tail부도 좀 더 round한 형태로 변경되는 것으로 나타났다. 특히 flat한 shoulder 에 의해 성장 결정의 중앙부의 sharp한 결정 tail이 round한 shoulder에 의해 제거될 수 있는 가능성이 있는 것으로 판단된다.

본 연구의 시뮬레이션 결과가 타당한지를 알아보기 위 하여 $\mathrm{CZ}$ 성장공정 중기의 시뮬레이션 결과를 제작한 사

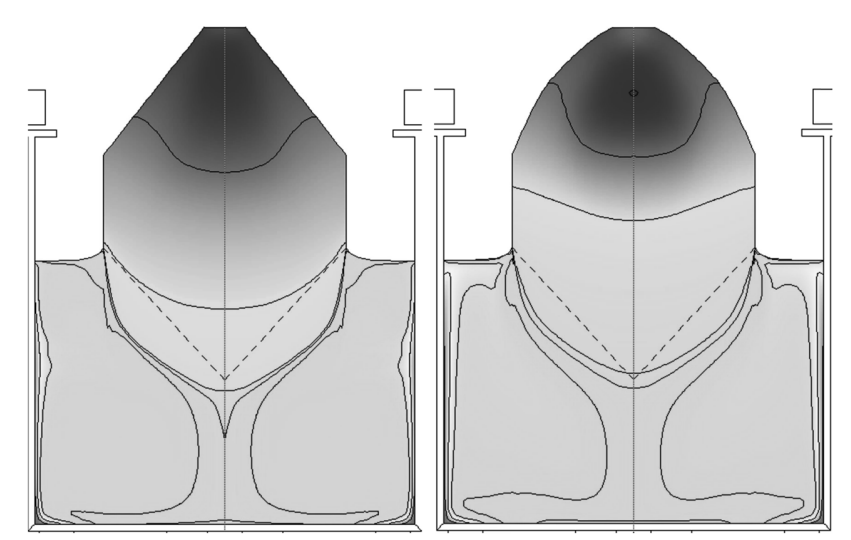

(a)

(b)

Fig. 6. Influence of the shoulder type on the crystal shape during the mid stage: (a) Flat type and (b) round type.
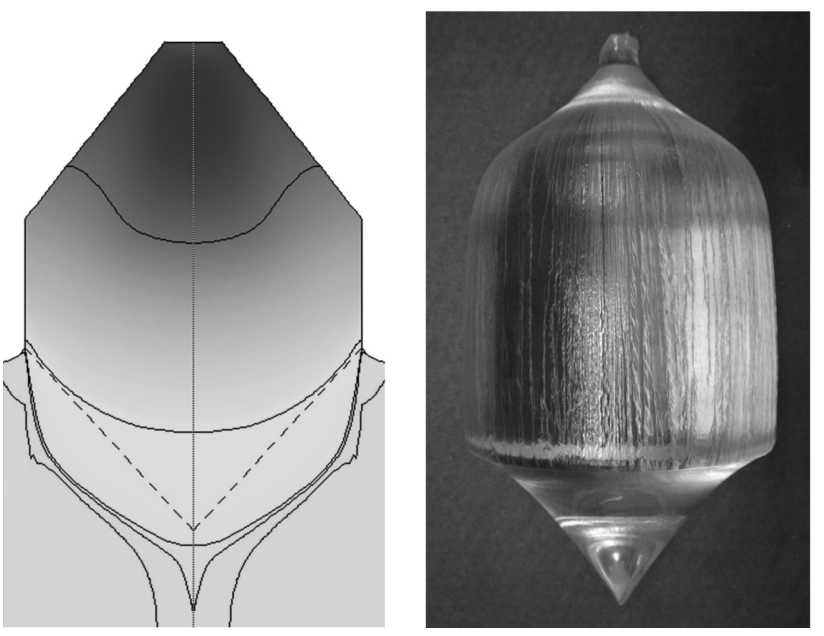

Fig. 7. Comparisons of the simulation results with the experiment results.

파이어 결정과 비교하여 Fig. 7에 나타내었다. 여기에서 알 수 있듯이, 실험 및 시뮬레이션 한 두 결정이 유사한 tail 형상을 가지고 있는 것을 확인 할 수 있었고, 본 연 구의 시률레이션 기법은 사파이어 $\mathrm{CZ}$ 성장공정 분석에 유용하게 적용할 수 있다고 사료된다.

\section{4. 결 론}

사파이어 결정의 $\mathrm{CZ}$ 성장공정은 고품질의 사파이어 단 결정을 성장시키기 위한 중요한 기술중의 하나이고, 고 품질의 단결정을 성장하기 위해서는 $\mathrm{CZ}$ 성장로 내부의 온도분포 및 유동분포, 결정의 형상 등에 대한 제어가 필 요하다. 본 연구에서는 유도 가열된 $\mathrm{CZ}$ 성장로에 대한 사파이어 결정의 성장공정을 $\mathrm{FEM}$ 을 사용하여 수치적으 로 분석하였다. 본 연구의 결과, 사파이어 결정의 성장이 진행됨에 따라 융액 내부의 온도 차이가 감소하여 유동 패턴이 하나에서 두 개로 분리되고, 성장된 결정의 내부 온도 차이는 증가하는 것으로 분석되었다. 또한 결정의 회전속도가 증가함에 따라 고온부는 도가니 표면에서 융 액의 내부로 이동하고, 유동 패턴 및 유속이 변경되어 고 -액 계면은 평편한 형태로 변화되는 것으로 분석되었다. 그리고 성장된 결정의 고-액 계면은 초기에 형성된 결정 의 shoulder 형상에 의해서도 영향을 받는 것으로 나타났 다. 그리고 시뮬레이션 결과를 실험적으로 성장한 결정의 형상과 비교하여 그 타당성 및 유용성을 확인하였다.

\section{참 고 문 헌}

[1] R. Feigelson, "50 years of progress in crystal growth", 
J. Crystal Growth 264 (2004) xi.

[2] M. Tavakoli, "Numerical study of heat transport and fluid flow during different stages of sapphire Czochralski crystal growth", J. Crystal Growth 310 (2008) 3107.

[ 3 ] C. Lu, J. Chen, C. Chen, C. Chen, W. Hsu and C. Liu, "Effects of RF coil position on transport processes during the stages of sapphire Czochralski crystal growth",
J. Crystal Growth 312 (2010) 1074.

[4] S. Demina, E. Bystrova, V. Postolov, E. Eskov, M. Nikolenko, D. Mashanin, V. Yuferev and V. Kalaev, "Use of numerical simulation for growing high quality sapphire crystals by the Kyropoulos method", J. Crystal Growth 310 (2008) 1443. 